\title{
Numerical and experimental investigation of formability in incremental sheet forming of particle reinforced metal matrix composite sheets
}

\author{
Shakir Gatea ${ }^{a}$, Thana Abdel Salam Tawfiq ${ }^{a}$, and Hengan Ou ${ }^{\text {b }}$ \\ a Department of Materials Engineering, Faculty of Engineering, University of Kufa, Al-Najaf, Iraq \\ ${ }^{b}$ Department of Mechanical, Materials and Manufacturing Engineering, Faculty of Engineering, \\ University of Nottingham, Nottingham, NG7 2RD, UK
}

\begin{abstract}
Metal matrix composites (MMCs) have a high strength-to-weight ratio, high stiffness, and good damage resistance under a wide range of operating conditions, making them a viable alternative to traditional materials in a variety of technical applications. Because of their high strength, composite materials are hard to deform to a significant depth at room temperature. As a result, additional treatments are required to enhance the composite's room ductility prior to deformation. In this investigation, as-received 6092Al/SiCp composite sheets (T6-condition) are heat treated to O-condition annealing to enhance its ductility in order to assess the influence of single point incremental forming (SPIF) parameters on the formability and fracture behavior of the $\mathrm{Al} / \mathrm{SiC}$ particle composite sheets at room temperature. Then the annealed sheets are heat treated to T6-condition to enhance the strength and achieve properties equivalent to as-received sheets properties. The results demonstrate that the $\mathrm{Al} / \mathrm{SiC}$ particle composite sheets with T6 treatment could not be deformed to the specified depth at room temperature due to low room ductility and that further treatment, such as $\mathrm{O}$ condition annealing, is required to enhance the room ductility. When annealed $\mathrm{Al} / \mathrm{SiCp}$ composite sheets are heat treated to $T 6$, the sheets exhibit properties comparable to the asreceived sheets. Al/SiC particle composite sheets with low SPIF parameters may have greater formability and fracture depth with low strain hardening curve.
\end{abstract}

Keywords: SPIF, Al/SiC particle composites, Formability, Forming parameters, Heat treatment Corresponding authors: Shakir Gatea, Shakir.Gatea@uokufa.edu.iq and Hengan Ou, $\underline{\text { H.Ou@nottingham.ac.uk }}$ 


\section{Introduction}

Aluminum matrix composite (AMC) materials reinforced with $\mathrm{SiC}$ particles offer significant promise for usage in the automotive, aerospace and energy industrial sectors. As a result, new techniques for deforming these composite sheets are necessary. Single point incremental forming (SPIF) is a flexible and easy to implementation sheet forming process, which only requires the use of a CNC milling machine to control the movement of a hemispherical tool and to deform the sheet in following a predefined tool path. Because of the unique characteristics of single point incremental forming, such as flexibility, cost-effectiveness, shortened time-to-market, and increased forming limit, the SPIF is a potential technology that can be developed further as an alternative production approach for composite sheets [1-4]. The impact of T6 treatment on the tensile properties of Al6061 and Al7108/SiCp composites was examined and compared to samples prior to T6 treatment. T6 treatment was shown to enhance the ultimate tensile strength of 6061 and 7108 composites [5]. The microstructure and interface of Al2124/10wt\% SiC particle composites were studied to better understand their behavior at high temperatures. The results revealed that a dispersed phase was formed around the SiC particles and also at the grain boundary [6]. Under different heat treatment conditions, the feasibility of using the SPIF to form 6092Al/SiCp sheets was investigated, and it was discovered that the composite sheets may be satisfactorily formed after O-condition annealing [7]. The impact of SPIF process parameters on a maximum forming angle in forming high strength AA5052-H32 alloy sheet has been experimentally examined. The results revealed that when step depth and tool diameter increased, the maximum forming angle decreased [8]. The influence of process parameters on the maximum forming angle was examined in the incremental forming of extra deep drawing steel sheets. The largest impact on the wall angle is affected by the tool diameter, followed by the feed rate and step depth [9].

The SPIF test was used to assess the formability of the aluminum alloy AA2024-0. The formability deteriorated with increased wall angle and step size [10]. To evaluate and enhance the process variables of the incremental sheet forming process using finite element simulations, the tool radius, step size, and friction coefficient were chosen as the key process variables. As a result of the FE simulations, the tool step size was found to be a major component for enhancing the formability of the incremental sheet forming process [11]. A simplified model of the SPIF of a truncated cone capable of estimating the thickness distribution was constructed using sequential limit analysis (SLA). It is 
proven that the SLA can predict the thickness distribution more precisely and efficiently than the comparable FEA technique [12]. Processing conditions also affect the quality of the SPIF parts made of carbon steel (DC01), stainless steel (304), and aluminum (A1050). Increased tool diameter, feed rate, and spindle speed enhance surface roughness and microstructure of formed components. Increased tool diameter and feed rate, on the other hand, have a negative impact on the component precision [13]. Aluminum Al30030 was used in a SPIF experimental test. The formability of the workpiece was seen to deteriorate as the step size was increased [14]. Using a cold incremental forming process, the effect of feed rate on the formability of DIN 1.0037 steel (St 37-2 steel) was studied. The results revealed that as the feed rate was increased, the formability decreased [15]. In order to examine the effect of tool diameter on formability, researchers tested the formability of a $\mathrm{Cp}$ Ti sheet in a cold ISF process. It was found that when the tool size was increased, the formability was decreased [16].

The workability of a thermoplastic matrix reinforced with glass fibers using the SPIF method was examined experimentally. It was observed that the SPIF may be utilized to deform the thermoplastic composite sheets [17]. The SPIF process's suitability for deforming composite/metal hybrid sheets was tested experimentally. The results demonstrated that the SPIF process may be utilized to create a composite/metal hybrid sheet component [18]. Numerical, analytical, and experimental studies were used to assess the formability of bimetal composite sheets (Cu-Al composite sheets) in the SPIF process. Surface roughness, formability, and forming force of bimetal composite sheets were discovered to follow similar patterns to single-layer sheets [19]. The SPIF process was used to evaluate the effect of annealing on the formability of Cu-St composite sheets. When the annealing temperature is raised, the formability of the $\mathrm{Cu}$-St composite sheets was improved [20, 21].

The literature clearly shows that attempts have been made to evaluate the influence of SPIF parameters on monolithic alloys, but no study has been published to examine the effect of SPIF process parameters on particle-reinforced metal matrix composites materials. Al/SiC-T6 AMC sheets are hard to deform at room temperature because of their high strength. As a consequence, $\mathrm{O}$-condition annealing is used to improve the room ductility of $\mathrm{Al} / \mathrm{SiCp} \mathrm{AMC}$ sheets in this work. The capability of the SPIF process to deform the $\mathrm{Al} / \mathrm{SiCp} A M C$ sheets at room temperature is next examined, with a special focus on the effect of SPIF parameters on the formability of the Al/SiCp AMC sheets. Because high strength is important for the AMC materials, the annealed sheet is heat treated again to 
T6 condition for increased strength and desired characteristics similar to those of the asreceived sheet. This work is done by experimentation and finite element simulation.

\section{Experimental testing}

Al6092/SiC/17.5p AMC sheets having a thickness of $1.04 \mathrm{~mm}$ and received at T6-condition are used in this work. The main feature of $\mathrm{Al} / \mathrm{SiCp} \mathrm{AMC}$ material is its high strength. Nevertheless, due to its high strength, it is difficult to deform the AMC sheet to a specified shape at ambient temperature. As a result, in this research, the as-received 6092Al/SiCp AMC sheets (T6-condition) are heat treated to O-condition annealing to increase its ductility at room temperature, then the annealed sheet is heat-treated to T6condition to improve the strength again. The heat treatments (O-condition annealing and T6-treatment) were carried out in accordance with the ASM's recommendations.

To evaluate the effect of heat treatment on the mechanical properties of the $\mathrm{Al} / \mathrm{SiCp}$ AMC sheets, tensile tests were performed using an INSTRON testing machine with the asreceived sheet (T6), O-condition annealing sheet, and T6-treatment sheet. ASTM-E8 was used to design and manufacture the tensile specimens. The Vickers test was used to determine the effect of heat treatment on the hardness of Al/SiCp AMC sheets. For 15 seconds, the load was set at $5 \mathrm{~kg}$. The Vickers hardness test was performed in several locations, and the average value was recorded.

Under T6 and O-condition treatments, the SPIF test was performed on 6092Al/SiCp sheets with dimensions of $140 \mathrm{~mm} \times 140 \mathrm{~mm} \times 1.04 \mathrm{~mm}$. To minimise friction between the tool and the $\mathrm{Al} / \mathrm{SiCp}$ sheet, the Rocol RDT grease compound was employed as lubricant. A hyperbolic truncated cone with varying wall angles (from $22^{\circ}$ to $80^{\circ}$ ) was used to analyse the formability and fracture position in the 6092Al/SiCp sheets. The thickness, fracture depth, fracture wall angle, and stress-strain curves were all related to the findings of the SPIF testing. The tests were carried out at three different feed rates (1000, 2000 , and $3000 \mathrm{~mm} / \mathrm{min}$ ), with a tool diameter of $10 \mathrm{~mm}$ and a step size of $0.2 \mathrm{~mm}$. The deformed components were sectioned from the middle for two portions to analyse the thickness distribution of the SPIF components along the deformed wall.

\section{Finite Element Simulation}

In this work, Abaqus/Explicit software is used to do finite element simulation of single point incremental forming. The SPIF process's finite element model is made up of four separate parts: a forming tool, a sheet, a blank holder, and a backing plate. Analytical rigid bodies are 
used to simulate the forming tool, holder, and backing plate. The $\mathrm{Al} / \mathrm{SiCp} \mathrm{AMC}$ is represented as a deformable body with dimensions of $140 \times 140 \times 1.04 \mathrm{~mm}$. A surface to surface contact state is assigned between the forming tool and the top surface of the sheet, and between the lower surface of the sheet and the inner surface of the backing plate. To save processing time, mass scaling technique was utilized.

The AMC sheet meshed with a 4-node shell element (S4R). The major goal of this simulation was to predict the deformation of a $6092 \mathrm{Al} / \mathrm{SiCp}$ sheet during SPIF, with special attention paid to the effect of the SPIF parameters on the results. The simulation parameters are tool diameter, step size, and feed rate. The Coulombs friction law was used, with a friction coefficient of 0.1 between the $\mathrm{Al} / \mathrm{SiCp}$ sheet and the tools (forming tool, holder, and backing plate). The FE simulation is terminated when the depth of the hyperbolic truncated cone approaches the experimental depth. Table 1 shows the SPIF process parameters that were used for simulations.

Table 1 The SPIF Process parameters

\begin{tabular}{cccc}
\hline Parameter & Level 1 & Level 2 & Level 3 \\
\hline Tool diameter $(\mathrm{mm})$ & 8 & 10 & 12 \\
Step down $(\mathrm{mm})$ & 0.2 & 0.4 & 0.6 \\
Feed rate $(\mathrm{mm} / \mathrm{min})$ & 1000 & 2000 & 3000 \\
\hline
\end{tabular}

\section{Results and Discussion}

The stress-strain curves of the Al6092/SiCp AMC sheet under different heat treatment conditions i.e., as-received sheet (T6), O-condition annealing, and T6 are shown in Figure 1 (a). The figure clearly shows that $\mathrm{O}$-condition annealing can significantly improve the formability of AMC sheets. When the as-received 6092AI/SiCp AMC sheets (T6-condition) are heat treated to $\mathrm{O}$-condition annealing, the elongation to fracture increases by $65 \%$, and the maximum value of stress is reduced by $34 \%$. When 0 -condition annealed sheets are heat treated to T6 condition, similar characteristics to the as-received sheets can be obtained with a little percentage increase in elongation to fracture (about 5\%) and a small percentage decrease in ultimate tensile stress (about $5 \%$ ).

The Vickers hardness of the Al/SiCp AMC sheets varies with heat treatment type; as-received sheets have a high hardness, which decreases by $58 \%$ during O-condition annealing and increases again when the O-condition annealed sheets are heat treated to T6-condition (see 
Figure $1(b))$. It can be concluded that there is a good correlation between the stress-strain curve and the hardness of $\mathrm{Al} / \mathrm{SiCp} \mathrm{AMC}$ sheets under different heat treatment conditions and that low stress-high strain and low hardness could be produced with O-condition annealing, which can improve the composite sheet's ductility at room temperature.

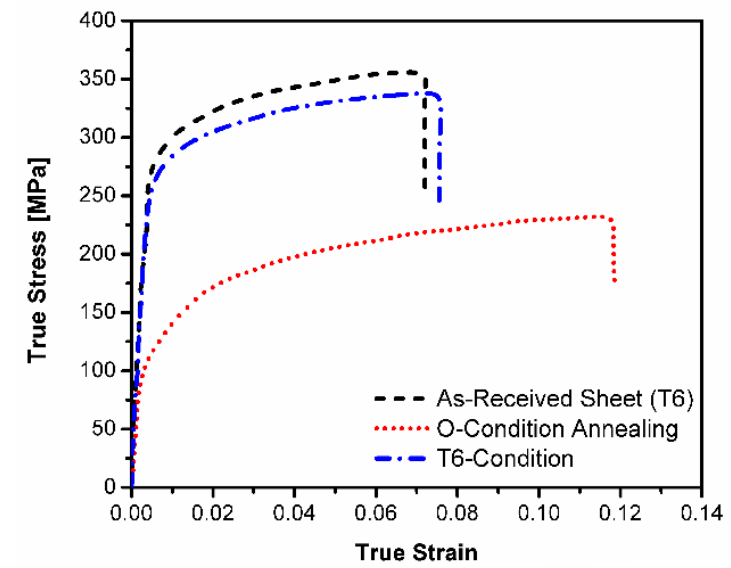

(a)

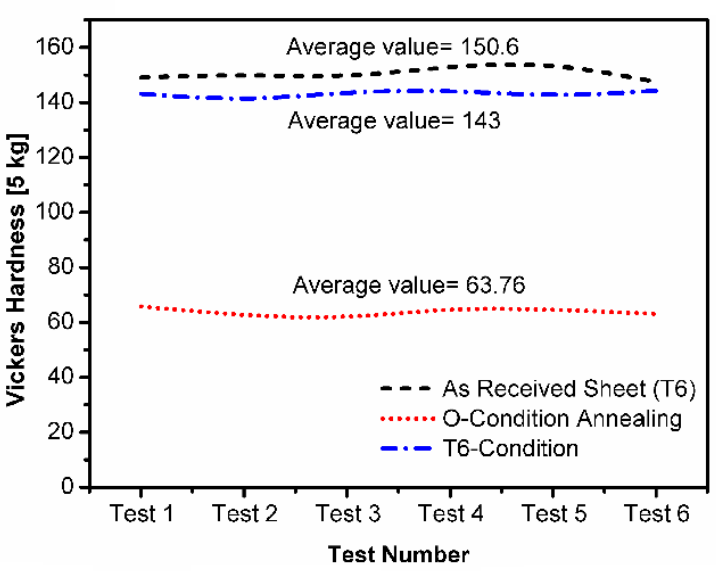

(b)

Figure 1 True stress-true strain curves (a) and Vickers hardness (b) of Al6092/SiC/17.5p under different heat treatment conditions.

The morphologies of the fracture surfaces of tensile specimens were examined using a scanning electron microscope (SEM) under different heat treatment conditions (as received sheet (T6), O-condition annealing, and T6-treatment). Figure 2 depicts the impact of the heat treatment on the fracture surface. In the T6 condition of as-received sheet and annealed sheet, the fracture surface exhibits shallow dimples with some broken SiC particles and debonding between the Al matrix and SiCp particles. However, after annealing, a high percentage of dimples were observed on the fracture surface of the tensile specimen. It is clear from Figures 1 and 2 that $\mathrm{O}$-condition annealing can be used to lower the strength of the $\mathrm{Al} / \mathrm{SiCp} \mathrm{AMC}$ sheets and to increase its ductility at room temperature. In conclusion, annealing the 6092Al/SiCp AMC sheets significantly improved their room ductility. T6-condition might be used to regain the strength and mechanical characteristics similar to as-received sheets.

As a result, two types of fracture mechanisms could be observed in this study: the first is a brittle fracture for material treated with T6. The second kind is ductile fracture, which occurs when a material is subjected to $\mathrm{O}$-condition annealing. 


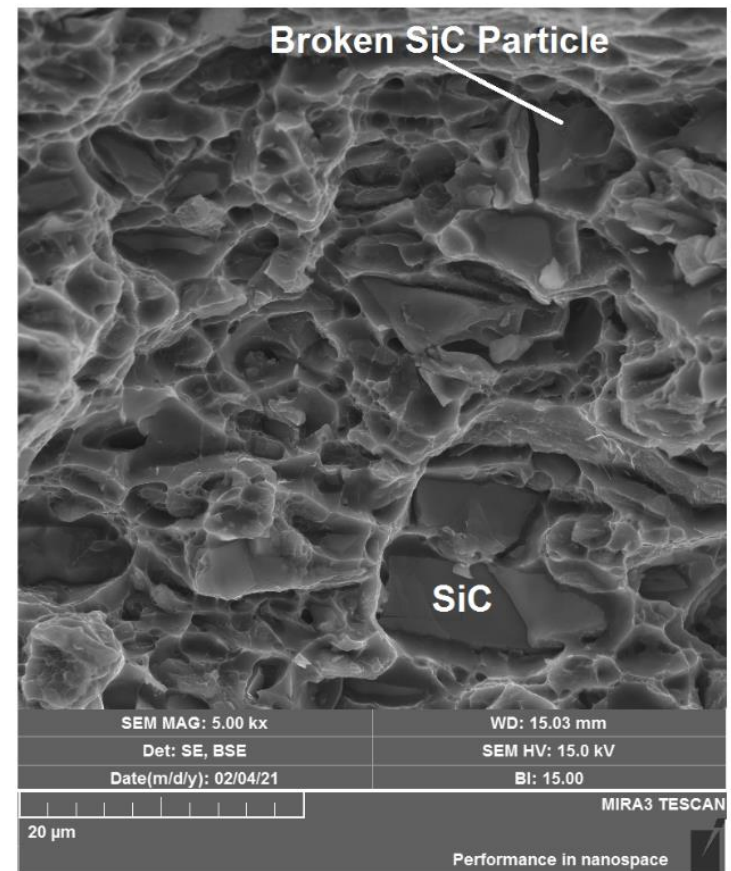

(a)

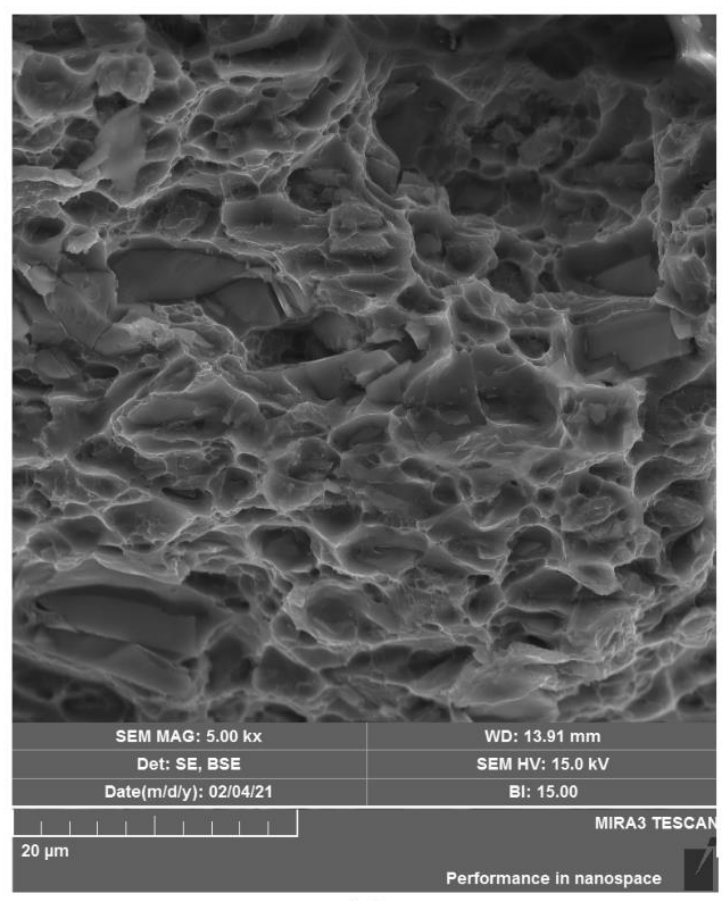

(c)

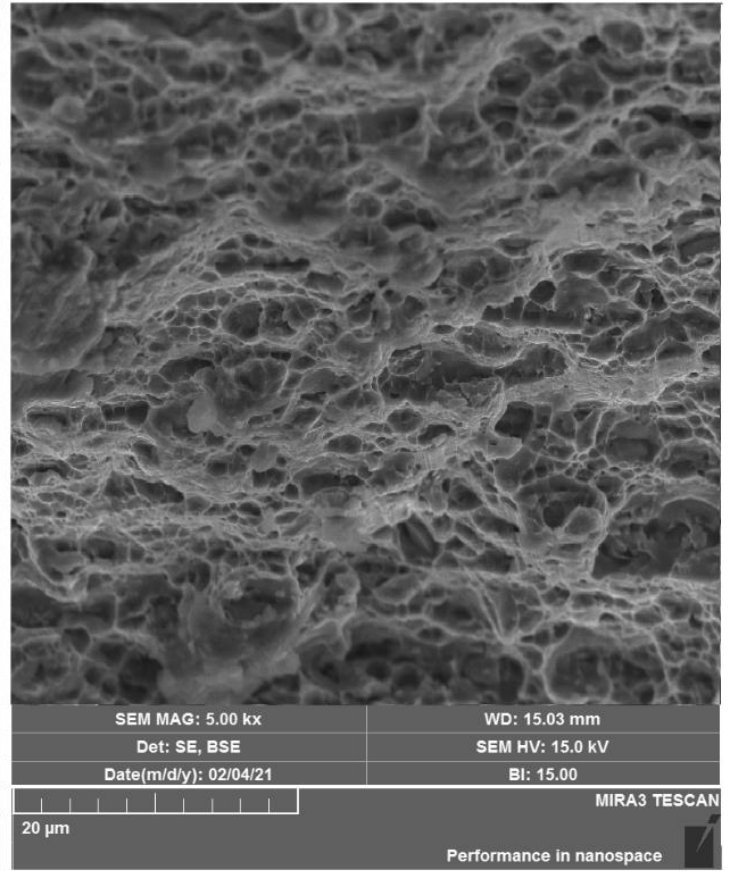

(b)

Figure 2 Fractography of 6092Al/SiCp with (a) T6-treament (as received), (b) O-condition annealing, and (c) T6-treatment.

The SPIF experimental tests were performed with T6 and O-condition treatments to deform a hyperbolic truncated cone shape with wall angles ranging from $22^{\circ}$ to $80^{\circ}$. Figure 3 (a) shows that the fracture occurs early in the T6 condition and has a substantial amount of springback. It is clear from Figure 3 (a) that without additional treatment, deforming the Al/SiCp AMC 
sheets at room temperature is difficult. To overcome this problem, O-condition annealing was employed to increase the ductility of the AMC sheets (see Figure 3 (b)). It can be observed in Figure 3 (b) that greater formability may be achieved with O-condition annealing with a little degree of springback. According to the observation, it is necessary to examine the influence of the SPIF parameters on the formability and fracture behavior of $\mathrm{Al} / \mathrm{SiC} \mathrm{AMC}$ sheets at room temperature due to O-condition annealing. As a result, the finite element simulation was applied to the $\mathrm{Al} / \mathrm{SiCp}$ sheets after O-condition annealing in this study.

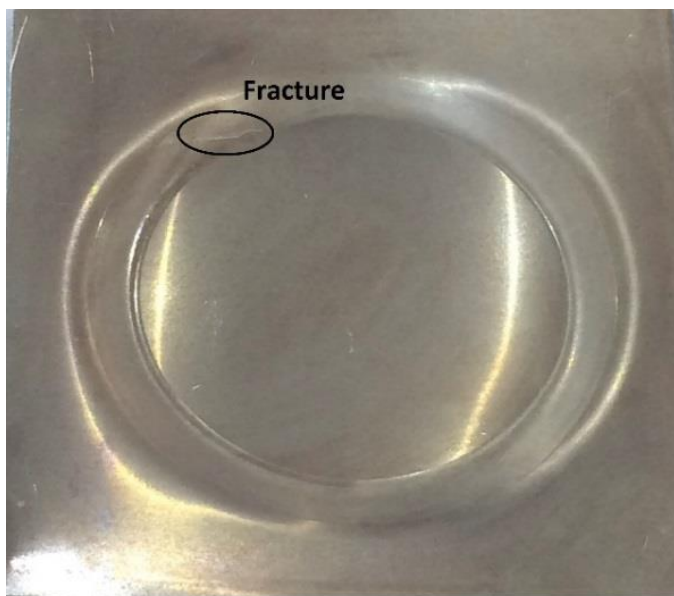

(a)

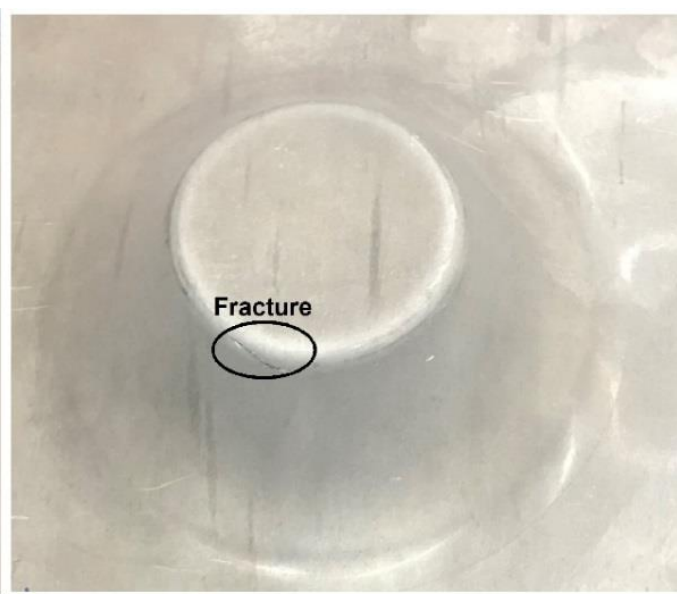

(b)

Figure 3 Heat treatment effects on the fracture depth of hyperbolic truncated cone: (a) after T6-treatment; (b) after O-condition annealing.

With constant step size and tool diameter of $0.2 \mathrm{~mm}$ and $10 \mathrm{~mm}$, three feed rates at 1000 , 2000 and $3000 \mathrm{~mm} / \mathrm{min}$ were used to examine the influence of the feed rate on the formability of $\mathrm{Al} / \mathrm{SiCp} \mathrm{AMC}$ sheets. Figure 4 depicts the thickness distribution along the wall of the $\mathrm{Al} / \mathrm{SiCp}$ hyperbolic truncated cone as well as the stress-strain curves. Figure 4 (a) shows that changing the feed rate can alter the thickness distribution, especially when the depth of the truncated cone is increased. The lowest thickness without fracture is reached with a low feed rate $(1000 \mathrm{~mm} / \mathrm{min})$, since a high forming angle may be produced with a low feed rate. The stress-strain curves of the deformed $\mathrm{Al} / \mathrm{SiC}$ truncated cone are shown in Figure 4 (b). The figure shows that strain hardening rises with feed rate, and high hardening is obtained with a high feed rate $(3000 \mathrm{~mm} / \mathrm{min})$. As a result, a high feed rate produces a high stress-low strain curve, whereas a low feed rate produces a low stress-high strain curve. The formability of the deformed cone is enhanced with a low level of feed rate and the equivalent strain is increased by $10 \%$ when the feed rate changes from 3000 to $1000 \mathrm{~mm} / \mathrm{min}$, while the maximum value of stress is reduced by $6 \%$.

It may be concluded that with a low feed rate, low stress values with high strain values can be obtained, and good formability can be obtained at these stress-strain values. Furthermore, 
there is a relationship between the thickness distribution and the stress-strain curves, low values of thickness without fracture could be achieved with a low stress-high strain curve.

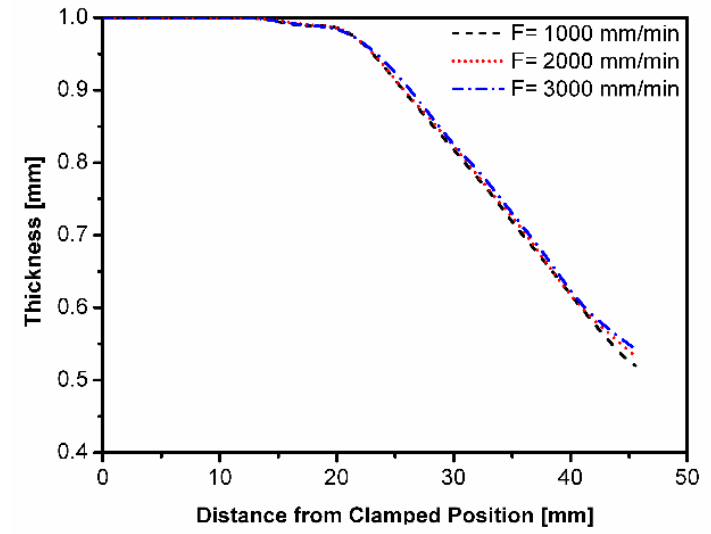

(a)

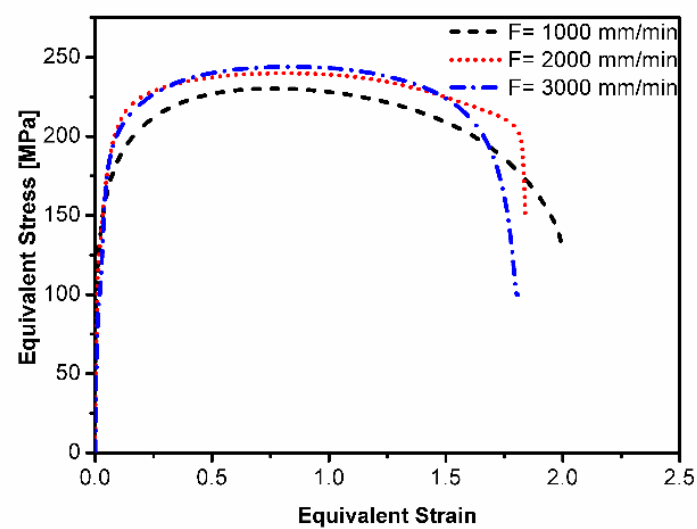

(b)

Figure 4 Thickness distribution (a) and stress-strain curves (b) at various feed rates.

Three tests were carried out to determine the influence of step size on the formability of the $\mathrm{Al} / \mathrm{SiCp} \mathrm{AMC}$ sheets at constant tool diameter and feed rate of $10 \mathrm{~mm}$ and $1000 \mathrm{~mm} / \mathrm{min}$, respectively. The step size was adjusted to three different values: $0.2,0.4$, and $0.6 \mathrm{~mm}$. The effect of step size on the thickness distribution and stress-strain values of deformed $\mathrm{Al} / \mathrm{SiCp}$ sheets is shown in Figure 5. Figure 5 (a) shows that with a small step size $(0.2 \mathrm{~mm})$, low thickness values with more depth may be produced, and these values rise as the step size increases, with the greatest thickness at fracture being seen with a $0.6 \mathrm{~mm}$ step size. This is because a localized deformation may be produced with small step sizes, but as the step size is increased, the deformation is no longer localized and the formability is reduced. Figure 5 (b) depicts the stress-strain curves for various step sizes. The figure clearly shows that the step size can affect the strain hardening in $\mathrm{Al} / \mathrm{SiCp}$ sheets; high strain hardening is generated with a big step size $(0.6 \mathrm{~mm})$, while low strain hardening is obtained with a small step size $(0.2 \mathrm{~mm})$. A low stress-high strain curve is created with small step size, while a high stress- low strain curve is generated with a big step size. When the step size is raised from 0.2 to $0.6 \mathrm{~mm}$, the effective strain decreases by $23 \%$ but the effective stress increases by $5 \%$. It is reasonable to conclude that low stress-high strain curve may be produced with small step sizes, which increases the fracture depth of the SPIF component and improves the formability of the Al/SiCp AMC sheets. 


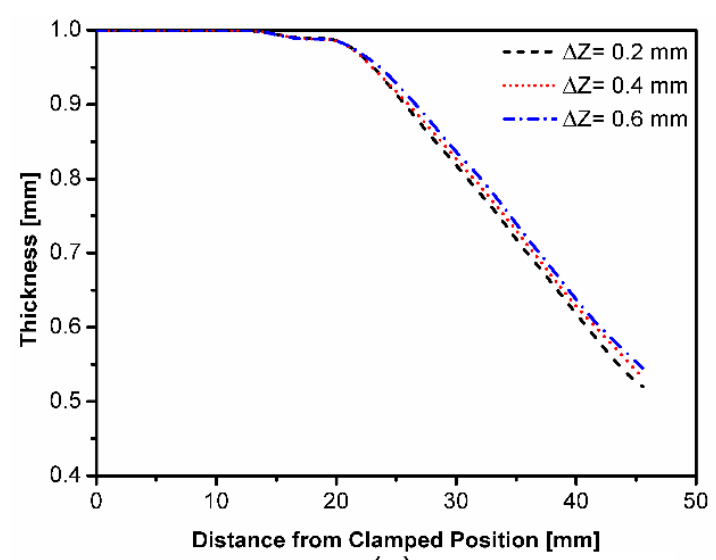

(a)

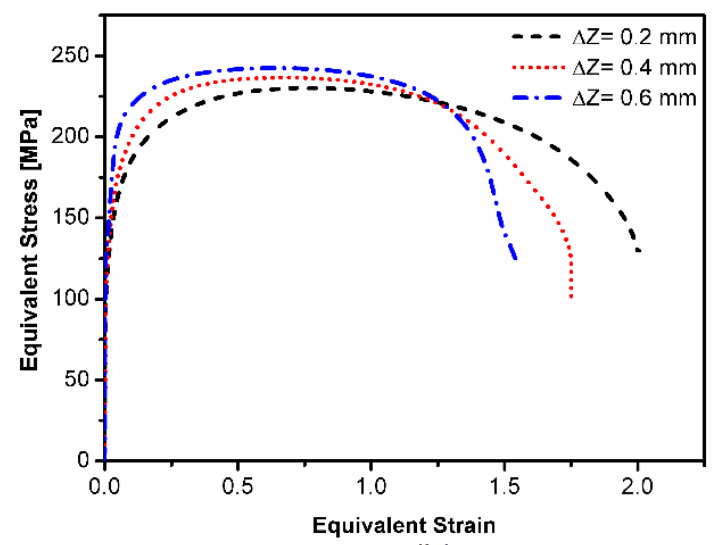

(b)

Figure 5 Thickness distribution (a) and stress-strain curves (b) at various step sizes.

To explain the influence of tool diameter on the formability of composite sheets, three sizes of forming tool diameter were used: 8,10 , and $12 \mathrm{~mm}$ with constant step size and feed rate of $0.2 \mathrm{~mm}$ and $1000 \mathrm{~mm} / \mathrm{min}$, respectively. Figure 6 (a) depicts the influence of tool size on the thickness distribution along the wall of an Al/Sicp AMC truncated cone and the stressstrain curves. The tool size clearly has a substantial influence on the thickness distribution and stress-strain curves. When the tool size is small, a low thickness distribution is generated without fracture and this distribution increases as the tool size increases. Formability decreases as tool diameter increases. Because the contact area expands as the tool size rises, the deformation does not remain localized as it does with a small tool size. Figure 6 (b) further shows that the large tool has a significant influence on the strain hardening behavior of the $\mathrm{Al} / \mathrm{SiCp} \mathrm{AMC}$ sheet, the strain hardening increases with tool diameter and the small tool obtaining minimal strain hardening in the composite sheet. With a small tool size, high strain values can be produced, and these values decrease as the tool size increases. When the tool diameter was changed from 8 to $12 \mathrm{~mm}$, the decrease in strain was $27 \%$ and the percentage of rising in stress was $14 \%$. When the impact of SPIF process parameters on AI/SiCp AMC sheets is compared, tool size is the most sensitive, followed by the step size and feed rate. 


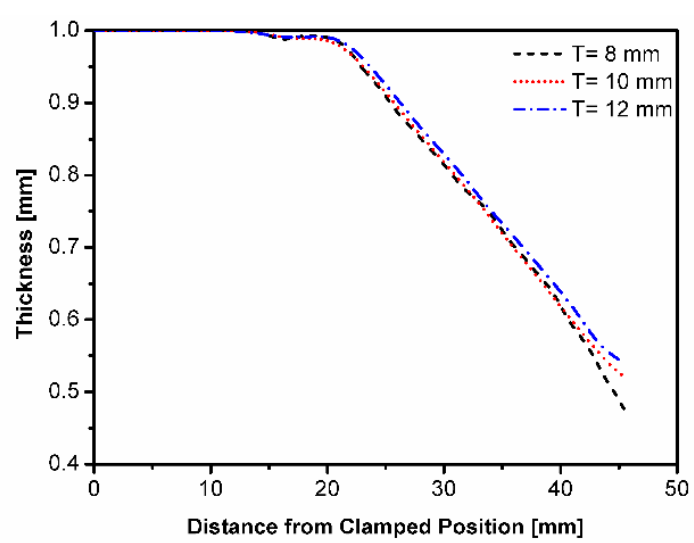

(a)

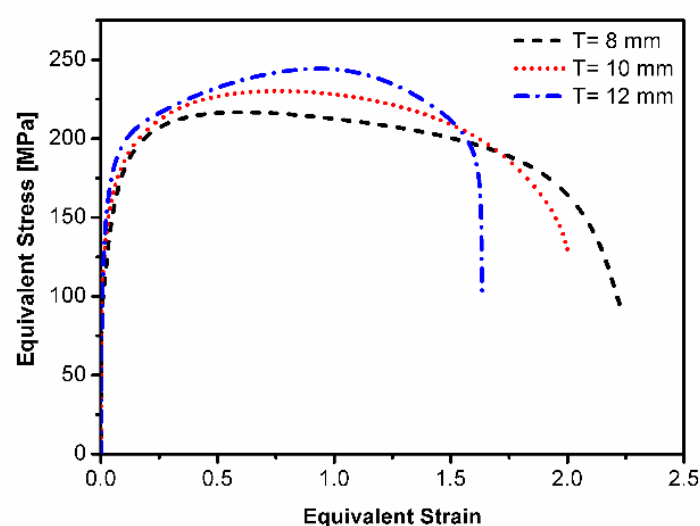

(b)

Figure 6 Thickness distribution (a) and stress-strain curves (b) at various tool sizes.

Figure 7 depicts the predicted distribution of equivalent plastic strain on the hyperbolic truncated cone under various conditions. Small values of strain are obtained at the beginning of the SPIF, and these values rise with cone depth, with the greatest value of equivalent plastic strain being in the transition zone between the inclined wall of the truncated cone and the base of the cone. The SPIF parameters may change the maximum value of predicted strain, and high strain (high formability) could be obtained with a low level of the SPIF parameters (step size $(Z)=0.2 \mathrm{~mm}$, feed rate $(F)=1000 \mathrm{~mm} / \mathrm{min}$, and tool diameter $(T)=8 \mathrm{~mm}$ ). The tool size, followed by the step size and feed rate, has a substantial influence on the formability of Al6092/SiCp AMC sheets. 


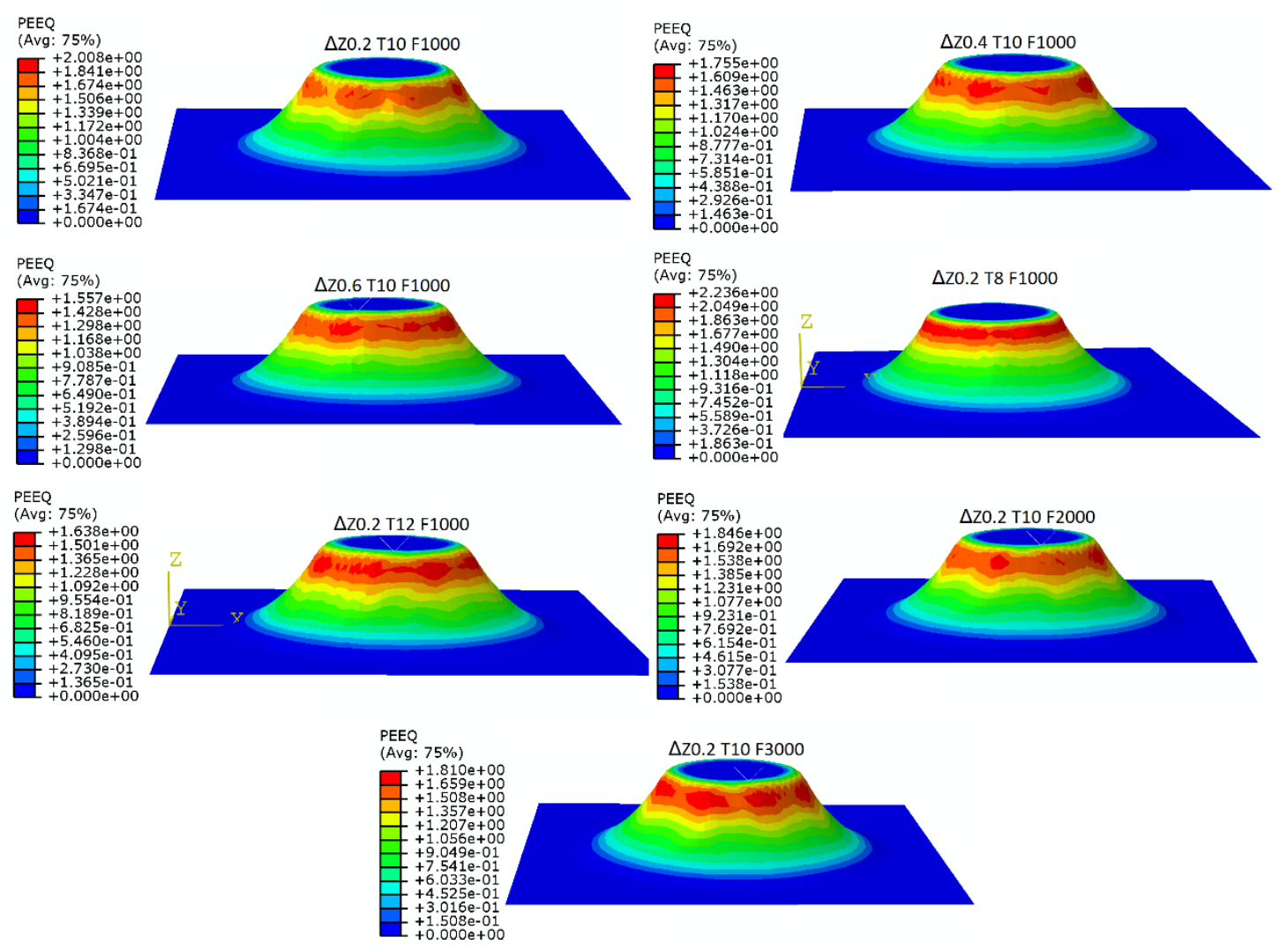

Figure 7 The distribution of equivalent strain obtained from a numerical simulation of a hyperbolic truncated cone under various forming conditions.

Figure 8 depicts the experimental fracture depth and wall angle. According to the figure, greater formability (wall angle) may be achieved with a low feed rate, but fracture occurs early with a larger feed rate, as shown in Figure 8 (a). The composite materials' sensitivity to strain rate may explain the early fracture with a high feed rate. The high strain rate causes stresses in the composite sheets to increase and fracture to occur more quickly, which is consistent with previous studies by Shakir Gatea et al. [22]. As indicated in Figure 9, the predicted thickness was compared to the experimental thickness to validate the FE results. The numerical and measured thickness results from the SPIF experiments have a strong correlation in terms of the thickness distribution of the hyperbolic truncated cone. 


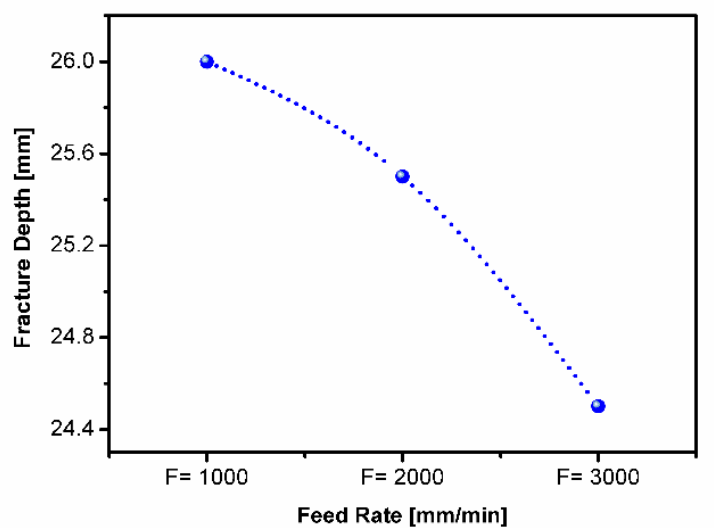

(a)

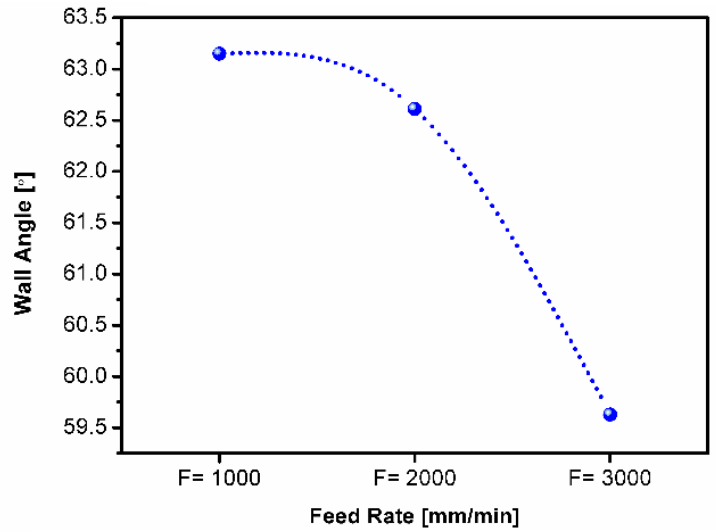

(b)

Figure 8 Experimental fracture depth (a) and wall angle (b) of a hyperbolic truncated cone of $\mathrm{Al} / \mathrm{SIC}$ particle at various feed rates.

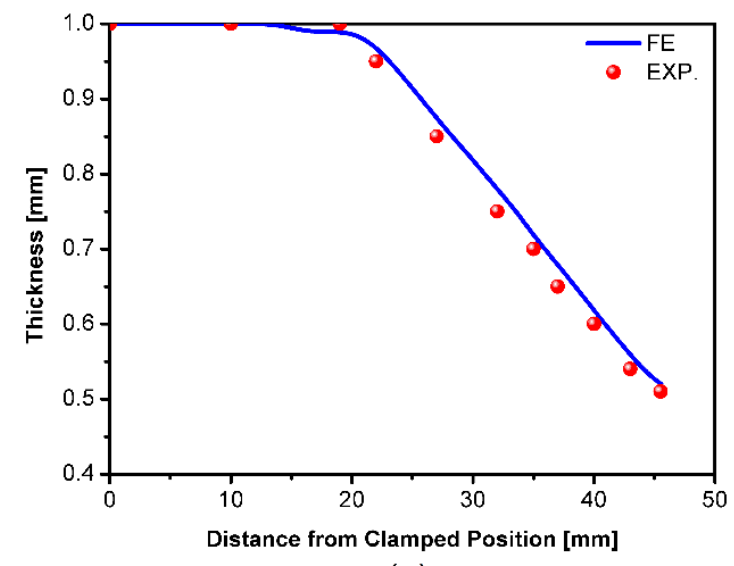

(a)

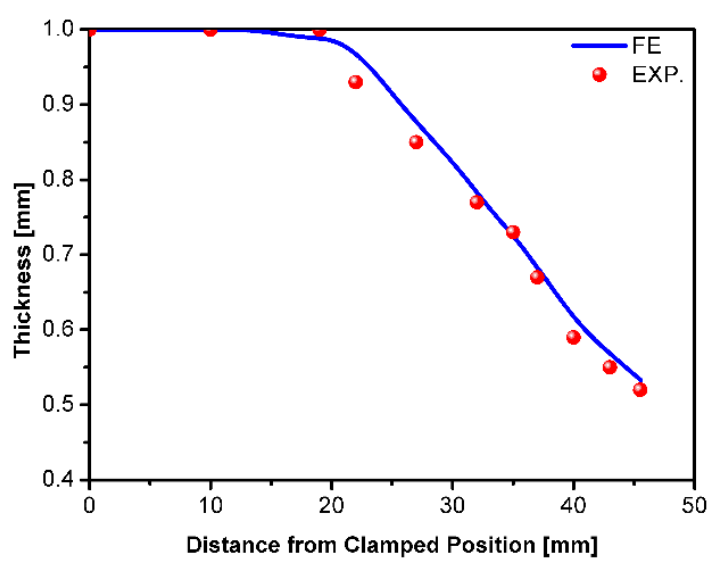

(b)

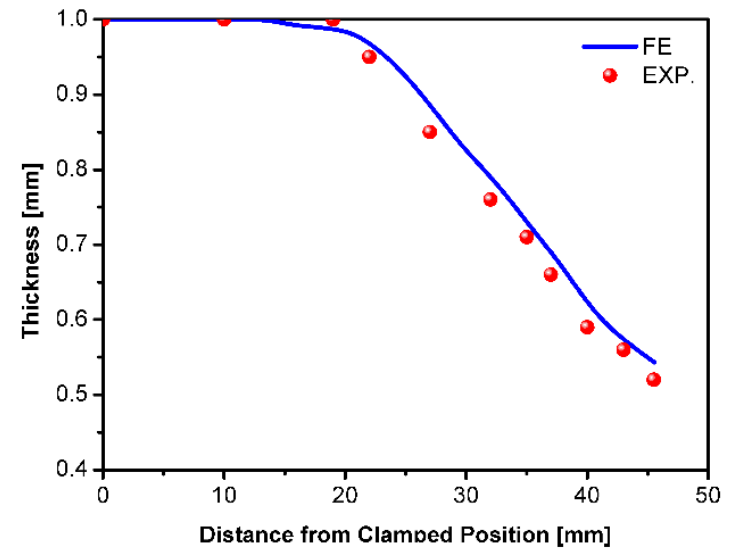

(c)

Figure 9 Simulated thickness results of the $\mathrm{Al} / \mathrm{SiCp}$ hyperbolic cone shape in comparison to the real forming experiment: (a) feed rate $1000 \mathrm{~mm} / \mathrm{min}$, (b) $2000 \mathrm{~mm} / \mathrm{min}$, and (c) 3000 $\mathrm{mm} / \mathrm{min}$. 


\section{Conclusions}

The major goal of this study is to improve the ductility of the Al/SiCp AMC sheets and to investigate the capability of the SPIF process to deform the AMC sheets, with a particular focus on the influence of SPIF parameters on the formability of the AMC sheets under O-condition annealing. The findings revealed that fracture morphology changes depending on the treatment conditions and the AI/SiC AMC sheets with T6 treatment could not be deformed to the specified depth at room temperature because of the poor ductility and that additional treatment, such as O-condition annealing, is necessary to improve the room ductility. Furthermore, the $\mathrm{Al} / \mathrm{SiCp} \mathrm{AMC}$ sheets with O-condition annealing are sensitive to the SPIF parameters, with low levels of the SPIF parameters achieving acceptable formability and fracture depth. With a low level of SPIF parameters, strain hardening in Al/SiCp sheets may be minimised. The Al/SiCp AMC sheets are the most sensitive to tool size in the SPIF process, followed by the step size and feed rate. When annealed Al/SiCp AMC sheets are heat treated to $\mathrm{T6}$, the sheets exhibit properties comparable to the as-received sheets.

\section{Acknowledgements}

The authors would like to express their gratitude to Professor Hui Long and Mr. Jamie Booth of the Department of Mechanical Engineering at the University of Sheffield in the United Kingdom for their assistance with the ISF testing.

\section{References}

1. Gatea, S., H. Ou, and G. McCartney, Review on the influence of process parameters in incremental sheet forming. The International Journal of Advanced Manufacturing Technology, 2016. 87(1): p. 479-499.

2. Peng, W., H. Ou, and A. Becker, Double-sided incremental forming: a review. Journal of Manufacturing Science and Engineering, 2019. 141(5).

3. Zhu, H., H. Ou, and A. Popov, Incremental sheet forming of thermoplastics: a review. The International Journal of Advanced Manufacturing Technology, 2020: p. 1-23.

4. Mishnaevsky Jr, L., K. Derrien, and D. Baptiste, Effect of microstructure of particle reinforced composites on the damage evolution: probabilistic and numerical analysis. Composites Science and Technology, 2004. 64(12): p. 1805-1818.

5. El-Sabbagh, A.M., M. Soliman, M.A. Taha, and H. Palkowski, Effect of rolling and heat treatment on tensile behaviour of wrought Al-SiCp composites prepared by stircasting. Journal of Materials Processing Technology, 2013. 213(10): p. 1669-1681.

6. Mandal, D. and S. Viswanathan, Effect of heat treatment on microstructure and interface of SiC particle reinforced 2124 Al matrix composite. Materials Characterization, 2013. 85: p. 73-81.

7. Gatea, S., F. Chen, H. Long, and H. Ou, Deformation and fracture of AMC under different heat treatment conditions and its suitability for incremental sheet forming. Procedia engineering, 2017. 207: p. 848-853. 
8. Mulay, A., S. Ben, S. Ismail, and A. Kocanda, Experimental investigations into the effects of SPIF forming conditions on surface roughness and formability by design of experiments. Journal of the Brazilian Society of Mechanical Sciences and Engineering, 2017. 39(10): p. 3997-4010.

9. Kurra, S., N. Swetha, C. Vinodh Reddy, and S. Regalla, Experimental and finite element studies of single stage incremental forming process: effect of process parameters on maximum wall angle and thickness distribution. Advances in Materials and Processing Technologies, 2018. 4(2): p. 322-334.

10. Kumar, A., V. Gulati, P. Kumar, V. Singh, B. Kumar, and H. Singh, Parametric effects on formability of AA2024-O aluminum alloy sheets in single point incremental forming. Journal of Materials Research and Technology, 2019. 8(1): p. 1461-1469.

11. Nguyen, D., J. Park, H. Lee, and Y. Kim, Finite element method study of incremental sheet forming for complex shape and its improvement. Proceedings of the Institution of Mechanical Engineers, Part B: Journal of Engineering Manufacture, 2010. 224(6): p. 913-924.

12. Mirnia, M., B.M. Dariani, H. Vanhove, and J. Duflou, An investigation into thickness distribution in single point incremental forming using sequential limit analysis. International Journal of Material Forming, 2014. 7(4): p. 469-477.

13. Radu, M. and I. Cristea, Processing metal sheets by SPIF and analysis of parts quality. Materials and Manufacturing Processes, 2013. 28(3): p. 287-293.

14. Duflou, J., Y. Tunckol, A. Szekeres, and P. Vanherck, Experimental study on force measurements for single point incremental forming. Journal of Materials Processing Technology, 2007. 189(1-3): p. 65-72.

15. Hussain, G., L. Gao, and Z. Zhang, Formability evaluation of a pure titanium sheet in the cold incremental forming process. The International Journal of Advanced Manufacturing Technology, 2008. 37(9): p. 920-926.

16. Han, F. and J.-h. Mo, Numerical simulation and experimental investigation of incremental sheet forming process. Journal of Central South University of Technology, 2008. 15(5): p. 581-587.

17. Conte, R., G. Ambrogio, D. Pulice, F. Gagliardi, and L. Filice, Incremental sheet forming of a composite made of thermoplastic matrix and glass-fiber reinforcement. Procedia engineering, 2017. 207: p. 819-824.

18. Fiorotto, M., M. Sorgente, and G. Lucchetta, Preliminary studies on single point incremental forming for composite materials. International Journal of Material Forming, 2010. 3(1): p. 951-954.

19. Liu, Z. and G. Li, Single point incremental forming of CU-Al composite sheets: $A$ comprehensive study on deformation behaviors. Archives of civil and mechanical engineering, 2019. 19(2): p. 484-502.

20. Al-Ghamdi, K. and G. Hussain, SPIF of Cu/steel clad sheet: annealing effect on bond force and formability. Materials and Manufacturing Processes, 2016. 31(6): p. 758763.

21. Al-Ghamdi, K.A. and G. Hussain, On the comparison of formability of roll-bonded steel$\mathrm{Cu}$ composite sheet metal in incremental forming and stamping processes. The International Journal of Advanced Manufacturing Technology, 2016. 87(1): p. 267278.

22. Gatea, S., H. Ou, and G. McCartney, Deformation and fracture characteristics of Al6092/SiC/17.5 p metal matrix composite sheets due to heat treatments. Materials Characterization, 2018. 142: p. 365-376. 


\section{Declarations}

Paper title: Numerical and experimental investigation of formability in incremental sheet forming of particle reinforced metal matrix composite sheets incremental forming

Authors: Shakir Gatea, Thana Abdel Salam Tawfiq, and Hengan Ou

Funding (Not applicable)

Conflicts of interest/Competing interests (Not applicable)

Availability of data and material (Data and materials are available)

Code availability (Not applicable)

Authors' contributions (Shakir Gatea designed the study, performed experiments, and wrote the manuscript; Thana Abdel Salam Tawfiq performed experiments; Hengan Ou designed the study and contributed to the data interpretation)

Ethics approval (Not applicable)

Consent to participate (I am agreeing to participate)

Consent for publication (I am agreeing to publish this work)

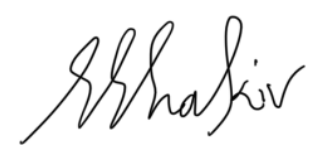

\section{Shakir Gatea}

$\mathrm{PhD}$ 